\title{
Transitioning Lumbar Fusions to Outpatient Using Midline Less Exposure Surgery Techniques with Transfacet and Mediolateral Cortical Bone Pedicle Screws
}

\author{
KR Chin ${ }^{1,2,3}$, FJR Pencle ${ }^{4}$, RM Harris II ${ }^{2,4}$, JA Seale ${ }^{3}$
}

\begin{abstract}
Objective: Posterior decompression and fusion have been the standard of treatment for degenerative disc disease as well as disc herniation. Recent advances in medicine and healthcare have shown a trend to move surgeries to the outpatient setting. The authors aim to assess the outcomes of unilateral cortical pedicle screw-rod construct combined with a contralateral transfacet pedicle screw (TFPS) in the outpatient setting.

Methods: The medical records of 40 patients with prospectively collected data were retrospectively reviewed. Two cohort groups, bilateral traditional pedicle screws consisting of 20 patients and unilateral pedicle screw (UPS) rod construct with a contralateral transfacet pedicle screw (TFPS) consisting of 20 patients were created. Outcomes assessed include demographic age and body mass index (BMI). Functional visual analog scale (VAS) pain and owestry disability index (ODI) scores as well as, the complication rate was also assessed.

Results: There were 24 males and 16 females, age range $28-65$ years average $59.3 \pm 2.3$ years, with an average BMI of $28.6 \pm 0.9 \mathrm{~kg} / \mathrm{m}^{2}$. There was a significant improvement in pre-operative VAS and ODI in both groups, however, there was no intergroup significance $\mathrm{p}=0.733$ and 0.093 , respectively. The most common complaint was dermatome numbness which was present pre-operatively but persisted for six months postoperatively.

Conclusion: Combined unilateral pedicle screw with a contralateral facet screw (UPFS) has a similar safety profile with improvement in VAS and ODI postoperatively. This technique is an alternative that can be performed based on surgeon preference.
\end{abstract}

Keywords: Combined fixation, cortical bone trajectory pedicle screws, eligibility, facet screws, less exposure surgery, L5-S1, outpatient, posterior fixation

\section{Transición de fusiones lumbares al tratamiento de pacientes ambulatorios mediante técnicas de cirugía de menos exposición de línea media con tornillos transfacéticos y pediculares del hueso cortical mediolateral}

\author{
KR Chin ${ }^{1,2,3}$, FJR Pencle ${ }^{4}$, RM Harris II ${ }^{2,4}$, JA Seale $^{3}$
}

\begin{abstract}
RESUMEN
Objetivo: La fusión y descompresión posterior han sido el tratamiento estándar para la enfermedad degenerativa del disco, asi como para la hernia discal. Los recientes avances en medicina y salud han mostrado una tendencia a desplazar las cirugias al escenario ambulatorio. Los autores persiguen evaluar los resultados de la construcción de tornillo de barra pedicular cortical unilateral combinada con un tornillo pedicular transfacetario (TPTF) contralateral en el contexto ambulatorio.
\end{abstract}

From: ${ }^{1}$ Charles E. Schmidt College of Medicine at Florida Atlantic University, USA, ${ }^{2}$ Herbert Wertheim College of Medicine at Florida International University, USA, ${ }^{3}$ Less Exposure Surgery Specialists Institute (LESS Institute), USA and ${ }^{4}$ Less Exposure Surgery (LES) Society, USA.
Correspondence: Dr K Chin, Less Exposure Surgery Specialists Institute (LESS Institute), $1100 \mathrm{~W}$. Oakland Park Blvd. Suite \#3, Fort Lauderdale, FL, 33311, USA. Email: kingsleychin@thelessinstitute. com 


\begin{abstract}
Métodos: Se revisaron retrospectivamente las historias clínicas de 40 pacientes con datos recogidos prospectivamente. Se crearon dos grupos de cohorte: uno de 20 pacientes con tornillos pediculares bilaterales; $y$ otro de 20 pacientes con construcciones de tornillo de barra pedicular unilateral (TBPU) con tornillos pediculares transfacetarios (TPTF). Los resultados evaluados incluyen demografia, edad, e indice de masa corporal (IMC). También se evaluaron el dolor según la escala visual analógica (EVA) y las puntuaciones del índice de discapacidad de Owestry (IDO), así como la tasa de complicaciones.

Resultados: Habia 24 varones y 16 hembras, mujeres, rango de edad 28 a 65 años, promedio 59.3 \pm 2.3 años, con un IMC promedio de $28.6 \pm 0.9 \mathrm{~kg} / \mathrm{m}^{2}$. Hubo una mejoría significativa en el preoperatorio con respecto a EVA e IDO en ambos grupos. Sin embargo, no hubo significación ninguna intergrupal, siendo $\mathrm{p}=0.733$ y 0.093, respectivamente. La queja más común fue el entumecimiento dermatomal que se presentaba en el preoperatorio, pero persistía luego por espacio de seis meses postoperatoriamente.

Conclusión: El tornillo pedicular unilateral combinado con un tornillo facetario contralateral (TFPU) tiene un perfil de seguridad similar con mejoras en VAS e IDO postoperatoriamente. Esta técnica es una alternativa que puede ser realizada basada en la preferencia del cirujano.
\end{abstract}

Palabras claves: fijación combinada, tornillos pediculares, trayectoria, hueso cortical, elegibilidad, tornillos facetarios, cirugía de menos exposición, L5 - S1, ambulatorio, fijación posterior

\title{
West Indian Med J 2017; 66 (3): 429
}

\section{INTRODUCTION}

The use of pedicle screw (PS) fusion techniques has been demonstrated as a standard for treatment with disabling back pain $(1,2)$. Biomechanical studies have demonstrated comparable results with the use of facet screws as an alternative to PS (3-5). The advent of less exposure surgery techniques has recently outlined a technique of bilateral transfacet pedicle screw (TFPS) fixation of the facet joint as an alternative to standard bilateral pedicle screw [BPS] (6). Several studies also investigated and compared TFPS and BPS. Suk et al demonstrated no significant differences in clinical outcomes and fusion rates between patients assigned to either unilateral or BPSs over a minimum follow-up of 24 months, in a comparative prospective study of 87 patients with degenerative spondylolisthesis (7).

As our healthcare system evolves and becomes more complex, there has been a growing trend to transition from inpatient surgeries to outpatient surgeries (8-12). The increased efficiency of surgical care is of the utmost importance because, due to the ageing of the baby boomers, there is a large expected forecasted growth of surgical work by the year 2020 (13). Because of both the desired efficiency associated with outpatient surgeries and their reduced cost, healthcare providers and hospitals alike, have become vested stakeholders in this transition from inpatient surgeries to outpatient surgeries. With regards to the lumbar spine, PS are the main instrumentation used for fixation (14). Although there is an increased-risk of complication associated with PS fixation, an alternative method using facet screws approaches fixation with a less exposure surgery strategy (3). The aim of this study is to demonstrate the feasibility of an unilateral pedicle screw (UPS) rod combined with a contralateral transfacet pedicle screws (TFPS) construct in the outpatient setting.

\section{SUBJECTS AND METHODS}

We reviewed the medical records of 40 patients treated by a single surgeon in an ambulatory surgery centre (ASC). There were two groups of 20 patients each, Group 1: control group of patients with single level posterior decompression with bilateral traditional pedicle screws at L5-S1. Group 2 patients had single level posterior spinal decompression with supplemental fixation using a unilateral cortical bone trajectory pedicle screw-rod construct combined with a contralateral transfacet pedicle screw fixation (UPFS) at L5-S1. Institutional review board approval for this study was attained as part of a cohort population. Indications for surgery, included chronic disabling low-back pain with or without leg pain secondary to degenerative discs and facet disease and/or Grade I spondylolisthesis with foraminal stenosis.

The primary diagnoses are listed in Table 1. All patients had failed a minimum of six weeks of conservative therapy, which included anti-inflammatory medications, physical therapy, therapeutic steroid injections and radiofrequency rhizotomies for patients with suspected facet-mediated axial back pain. Chronic but stable medical conditions included asthma, hypertension, diabetes mellitus, arthritis, hypercholesterolaemia and heart disease. All patients were medically cleared by their family practitioner and/or cardiologist where applicable and deemed fit for surgery by the Anaesthesiologists as American Society of Anaesthesiologists (ASA) I, II, or III. ASA Physical Status Classification Sytem - IV patients were excluded from outpatient surgery.

The operating surgeon had extensive experience performing the procedure in academic and private hospitals, as if the patients were in an outpatient setting, until reproducible in the hospital, prior to commencing in an ambulatory setting. As such, a standard eligibility criteria for outpatient spine 
surgery was applied for lumbar fusion $(10,11)$. Patients were discharged from the recovery room with a responsible adult to drive them home only after they were deemed to be fully alert by an experienced registered nurse and the attending anaesthesiologists and were neurologically intact by the attending spine surgeon.

Transfer agreements were in place between the ASC and with neighboring hospitals within 30 minutes, if patients develop any serious problems $(10,11)$. Patients were instructed on postoperative protocol (11). The first clinic follow-up visit was at two weeks postoperative and physical therapy was started. Follow-up continued at six weeks, 6, 12, 18 and 24 months.

Fusion was aided with interbody polyetheretherketone (PEEK) cages assessed radiologically using fluoroscopy for evidence of interbody placement. Additionally, bone grafts were used to aid fusion and included, demineralized bone matrix (DBM), allograft cancellous chips and autograph laminectomized bone. All patients received supplemental posterior fixation with the use of transfacet pedicle screws and/ or standard pedicle screws and rods. Functional outcome measures were collected from 2011 to 2014 and evaluated pre-operatively and postoperatively at 3, 6, 12, 18 and 24 months. Functional outcomes included, patient numeric rating scale or visual analog scale (VAS) for lower back pain (0-10), Oswestry disability index (ODI), surgeon operative time, blood loss and complication rates.

\section{Summary of operative technique}

Patients were placed prone on a Wilson frame, which was then cranked-up into maximum kyphosis to open the interlaminar spaces for decompression. Patients were given two grams of Cefazolin intravenously. A 22-gauge spinal needle was placed just lateral to the spinous processes, docking against the lamina of the intended spinal level under anteroposterior fluoroscopic guidance (15). Five-to-ten millilitres of $0.5 \%$ bupivacaine with epinephrine was injected into the paraspinal muscles. A midline vertical incision was then made and the spine exposed. The exposure was limited laterally to the facets since the facets were the intended fusion surfaces and not the transverse processes (Fig. 1).

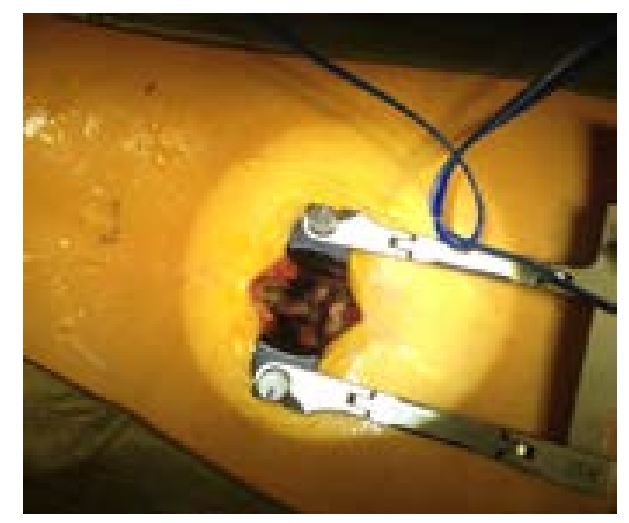

Fig. 1: Intra-operative photograph of midline incision with exposure to facets.
The supraspinous and interspinous ligaments were removed and the ligamentum flavum was elevated from the inferior lamina surface and the underside of the cephalad lamina using a curette. A Burr and Kerrison ronguers were used to create a hemilaminotomy/hemilaminectomy window to the disc. The ligamentum flavum was released laterally from the facets, cephalad and caudad from the laminae, and a medially-based flap retracted medially against the dura which protected the traversing nerve root.

The exiting nerve root was rarely visualized during this approach as it migrated cephalad in kyphosis away from the disc space. The traversing nerve root was protected underneath the ligamentum flavum flap. An annulotomy defect was created using a size 15 blade. Pituitaries, curettes and shavers were used to dislodge and remove disc material and exposed bleeding endplate. A custom bone funnel was placed into the disc space. Cancellous bone graft followed by microparticulate DBM and autograft laminectomized bone was packed tightly against the anterior longitudinal ligament (ALL). A posterior/transformational lumbar interbody fusion (PLIF/ TLIF) PEEK cage was placed straight through the annular window while preserving the facets, until it impacted the graft. The final position was confirmed fluoroscopically (Fig. 2).

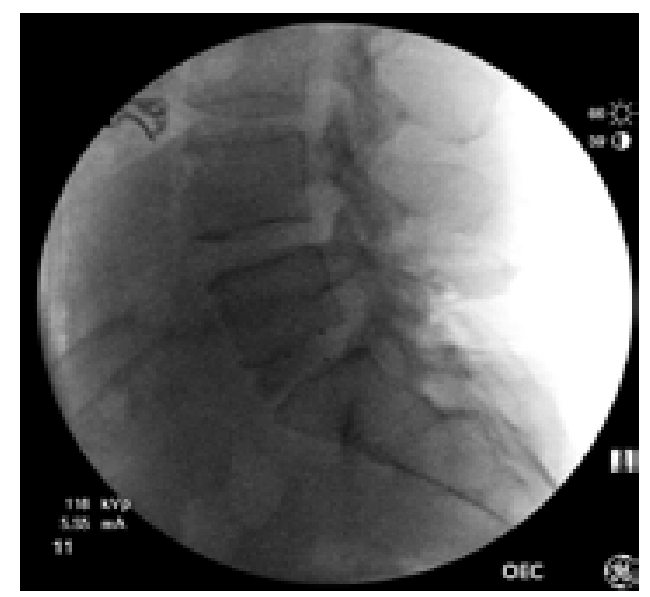

Fig. 2: Lateral fluoroscopic image confirming placement of polyetheretherketone (PEEK) cage at L5-S1.

At this point, complete decompression was achieved by removal of any remaining compressive ligamentum flavum. The spinous processes were retained along with the facets. The Wilson frame was then taken out of kyphosis and the patient's lumbar spine would visibly settle into lordosis. Fixation was placed through the facets unilaterally then contralateral cortical bone trajectory pedicle screw-rod construct placed (Fig. 3).

Fluoroscopic confirmation was performed (Fig. 4A/B). The wound was then closed in interrupted layers. No drains were placed during closure in any of the surgeries. 


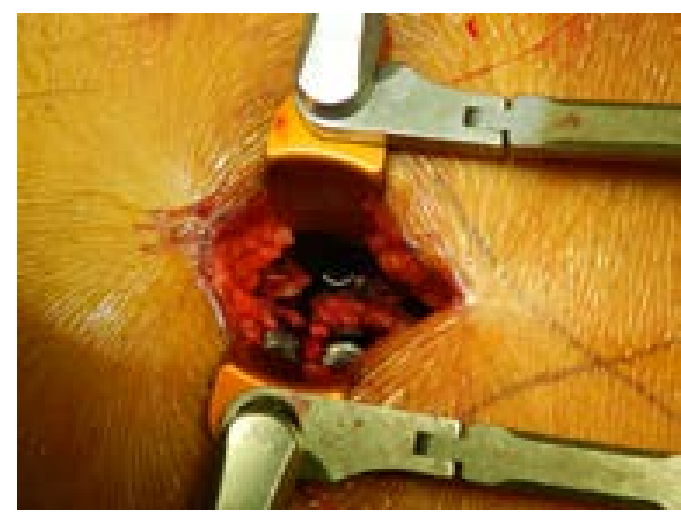

Fig. 3: Intra-operative photograph of combined fixation.

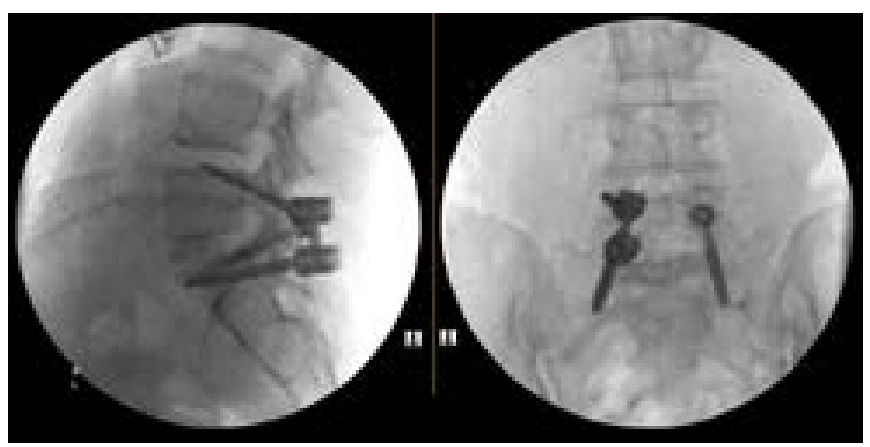

Fig. 4A/B: Lateral and antero-posterior fluoroscopic image confirming placement of fixation.

\section{Statistical analysis}

Statistical analysis was performed using SPSS v22 (IBM corporation, New York, USA). An independent sample student $t$-test was used to compare groups for continuous data and Chi-square used for categorical data. Continuous data comparisons were expressed as means with standard error. Tests were considered significant if $p<0.05$. Power analysis was performed based on a similar study to achieve a power of 0.8 and alpha of 0.05 ; a total sample size of 14 patients is necessary $(7,16)$.

\section{RESULTS}

A total of 40 patients were evaluated and two cohort groups created. Group 1 comprised of 20 patients with single level posterior decompression with bilateral traditional pedicle screws and Group 2 consisted of 20 patients of single level posterior spinal decompression with supplemental fixation using an unilateral cortical bone trajectory pedicle screw rod construct combined with a contralateral transfacet pedicle screw fixation (UPFS), 14 patients with left TFPS combined with right PS and six patients with right TFPS and left PS. Males represented $60 \%$ of patients overall, however, there was no difference in gender between groups, $p=0.519$. Overall age and BMI was $45 \pm 7$ years and $28.6 \pm 0.9 \mathrm{~kg} /$ $\mathrm{m}^{2}$, respectively. Mean age of Group 1 was $48 \pm 3$ years and Group 2 was $43 \pm 3$ years $(p=0.466)$. The mean BMI for
Groups 1 and 2 was $28.9 \pm 1.3 \mathrm{~kg} / \mathrm{m}^{2}$ and $28.3 \pm 1.3 \mathrm{~kg} / \mathrm{m}^{2}$, respectively, $p=0.876$. Demographics and diagnoses are detailed in Table 1.

Table 1: Cohort demographics with pathological levels and chief complaint

\begin{tabular}{lll}
\hline Variable & BPS & UPFS \\
\hline Age (years) & $48 \pm 3$ & $43 \pm 3$ \\
BMI $\left(\mathrm{kg} / \mathrm{m}^{2}\right)$ & $28.9 \pm 1.3$ & $28.3 \pm 1.3$ \\
Male & 13 & 11 \\
Female & 7 & 9 \\
Diagnosis & & \\
Herniated disc & 9 & 8 \\
Degenerative disc disease & 5 & 6 \\
Spondylosis (chronic pain) & 3 & 5 \\
Spondylolisthesis & 1 & 0 \\
Radiculopathy & 2 & 1 \\
\hline
\end{tabular}

BPS: Bilateral traditional pedicle screws; UPFS: unilateral pedicle screw-rod with a contralateral facet screw

\section{Functional outcomes}

Overall pre-operative VAS and ODI scores showed no significant difference between groups, $p=0.641$ and 0.975 , respectively. Group 1 mean pre-operative VAS scores for back pain, improved from $7.8 \pm 0.5$ to $2.5 \pm 0.7$ at two-year follow-up, $p$ $=0.001$. Pre-operative ODI scores improved from $40.8 \pm 3.3$ to $29.0 \pm 1.7$ at two-year follow-up, $p=0.004$. In Group 2, pre-operative VAS scores for back pain, improved from $7.8 \pm 0.4$ to $3.5 \pm 0.8$ at two year follow-up, $p=0.001$. Preoperative ODI scores improved from $48.9 \pm 4.0$ to $31.1 \pm 2.6$ at two-year follow-up, $p=0.001$. Comparison of Groups 1 and 2 revealed no statistical significance between postoperative VAS scores for back pain and ODI scores, $p=0.733$ and 0.093, respectively. Results are summarized in Table 2.

Table 2: Demonstrating pre-operative and two-year postoperative visual analog scale and Owestry disability index scores

\begin{tabular}{llll}
\hline Outcome & BPS & UPFS & Intergroup $\boldsymbol{p}$-value \\
\hline Pre-operative VAS Back & 7.8 & 7.8 & 0.641 \\
Pre-operative ODI & 40.8 & 48.9 & 0.975 \\
Postoperative VAS Back & 2.5 & 3.5 & 0.733 \\
Postoperative ODI & 29 & 31.1 & 0.093 \\
\hline
\end{tabular}

*All intragroup analysis achieved significance, $p<0.001$. BPS: Bilateral traditional pedicle screws; UPFS: unilateral pedicle screw-rod with a contralateral facet screw; VAS: visual analog scale; ODI: Owestry disability index

Analysis of Groups 1 and 2 surgical times revealed no statistical significance between $138 \pm 11$ minutes and $136 \pm 10$ minutes, respectively $(p=0.640)$. There was however, significance between groups EBL, Group 1 resulting with $152 \pm 28$ $\mathrm{mL}$ lost and Group 2 with $92 \pm 11 \mathrm{~mL}(p=0.02)$. 


\section{Follow-up}

Sagittal and axial computed tomography (CT) radiographs were evaluated by the authors (KRC, FJRP and JAS) to look for graft subsidence, implant failure and status of fusion. Fusion was defined as the absence of radiolucencies, and evidence of bridging trabecular bone within the fusion area (Fig. $5 \mathrm{~A} / \mathrm{B} / \mathrm{C})$.

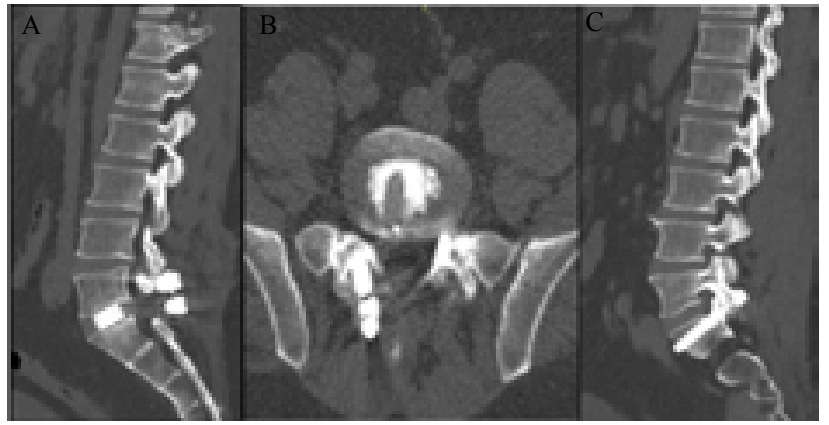

Fig. 5: Computed tomography demonstrating unilateral pedicle screw-rod and fusion; A: Sagittal view demonstrating bridging bone fusion; B: Axial view demonstrating bridging bone fusion; C: Sagittal view.

Fusion was achieved in 18 patients in Group 1 and all patients in Group 2. There was neither evidence of implant failure nor signs of non-union in the groups.

\section{Complications}

The most common postoperative complication overall observed in both groups was dermatome numbness in six patients (15\%) and persisted for an average of $6 \pm 1$ month. There was no significance between groups, $p=0.782$. Weakness was noted in three patients (15\%) in the bilateral traditional pedicle cohort with average grade 5-/5 and in two patients (10\%) in combined TFPS and PSR group with average grade 5-/5. Resolution of weakness was on average $9 \pm 3$ months. Patients in Group 1 complained of tenderness over the implant and this was more prominent in slimmer patients. Of note, the two patients without prior fusion required revision for intractable pain over pedicle screws which were exchanged for unilateral transfacet screws on the worst side.

\section{DISCUSSION}

This study aimed to directly compare the safety and procedural outcomes of unilateral pedicle screw-rod construct combined with a contralateral transfacet pedicle screw to the standard of bilateral traditional pedicle screw-rod constructs for treatment of decompressions at L5-S1. For the treatment of single level posterior spinal decompression at L5-S1, the newer approach mirrors the patient outcomes of the gold standard. Importantly, the results demonstrated that there was no statistical significance between the interventions of stabilization via bilateral traditional pedicle screw or unilateral pedicle screw-rod construct combined with an unilateral transfacet pedicle screw; as the $p$-values between the two groups for VAS and ODI scores were $p=0.733$ and $p=0.975$, respectively.
After 24 months, the mean ODI and VAS scores for patients who underwent the bilateral traditional pedicle screws as well as for the combined UPFS approach improved significantly. Estimated blood loss was significantly less in the UPFS group which can be due to less exposure surgery technique used for the procedure.

The finding of this report reflects evidence to support the use of UPFS as a means of intervention and treatment. A study by Awad et al, demonstrated similar outcomes, $p=0.99$ in patients who had minimally invasive transforaminal lumbar interbody fusion (MIS TLIF) in both BPS and UPFS (17). This method of intervention has also proven more feasible to the gold standard in other disease related back deformities that cause pain and disfigurement. The effectiveness of the procedure has been measured in the treatment of adolescent idiopathic scoliosis that have undergone posterior spinal arthrodesis (18). With the exception of the correction of upper thoracic curves, the unilateral rod construct with unilateral transfacet screw proved more feasible than fixation by a bilateral construct because, it not only mirrored the gold standard in excellent deformity correction, but it was also associated with decreased surgical time, decreased intra-operative blood loss, reduced costs and increased patient satisfaction (18).

From an economic viewpoint, unilateral pedicle fixation is considered by many as a cheaper surgery. According to Eliades et al (19), hospital costs were significantly lower for those who promoted the use of unilateral pedicle screw fixation due to less hardware and metal required for each surgery (19). As for scoliosis treatment, implant costs were reduced by a mean of $35 \%$ for those who underwent fixation by unilateral pedicle screw-rod construct with contralateral transfacet screw. Reduced surgery cost with effective treatment usually yields higher patient satisfaction. In addition, the new approach is a less invasive intervention (19). Similar to the treatment of juvenile scoliosis, our results indicated decreased intra-operative bleeding, which can be attributed to the surgery being less invasive (20).

The authors report no biases or conflict of interest. The authors note the following strengths and limitations. The main strengths of this study are using an adequate sample size based on previous studies. The outcomes assessed include, patient and surgeon factors which were independently analysed. Limitations of this study include the fact that it was a retrospective review of data collected in two cohort populations prospectively. The transition of spine surgery to the outpatient setting is on a rapid growth curve. As less exposure surgery techniques continue to be refined, the need for evidence-based research on outcomes and complications need to be demonstrated.

\section{CONCLUSION}

This paper provides evidence for the safety and equivalent outcomes of combined unilateral PSR with contralateral TFPS with a similar safety profile. Further studies and continued clinical investigations are needed as the expansion of outpatient spine surgery evolves. 


\section{AUTHORS' NOTE}

Conflicts of interest and sources of funding: We did not seek or receive any funding from the National Institutes of Health (NIH), Wellcome Trust, Howard Hughes Medical Institute (HHMI), or others for this work. Dr.KR Chin is a shareholder in and receives other benefits from SpineFrontier Inc., neither of the other authors (FJRP, RMH and JAS) have any potential conflicts of interest to declare for this work. The device(s)/ drug(s) is/are FDA-approved by the national corresponding agency for this indication.

\section{REFERENCES}

1. Roy-Camille R, Saillant G, Mazel C. Internal fixation of the lumbar spine with pedicle screw plating. Clin Orthop and Relat Res 1986; 203: 7-17.

2. Gaines RW, Jr. The use of pedicle-screw internal fixation for the operative treatment of spinal disorders. J Bone Joint Surg Am 2000; 82: 1458-76.

3. Ferrara LA, Secor JL, Jin BH, Wakefield A, Inceoglu S, Benzel EC. A biomechanical comparison of facet screw fixation and pedicle screw fixation: effects of short-term and long-term repetitive cycling. Spine 2003; 28: $1226-34$.

4. Burton D, McIff T, Fox T, Lark R, Asher MA, Glattes RC. Biomechanical analysis of posterior fixation techniques in a 360 degrees arthrodesis model. Spine 2005; 30: 2765-71.

5. Harris BM, Hilibrand AS, Savas PE, Pellegrino A, Vaccaro AR, Siegler S et al. Transforaminal lumbar interbody fusion: the effect of various instrumentation techniques on the flexibility of the lumbar spine. Spine 2004; 29: E65-70.

6. Chin KR, Seale J, Cumming V. Mini-open or percutaneous bilateral lumbar transfacet pedicle screw fixation: a technical note. J Spinal Disord Tech 2015; 28: 61-5.

7. Suk KS, Lee HM, Kim NH, Ha JW. Unilateral versus bilateral pedicle screw fixation in lumbar spinal fusion. Spine 2000; 25: 1843-7.

8. Services U. S.D.o.H.a.H., Medicare Ambulatory Surgical Center-Value Based Purchasing Implementation Plan. 2015.

9. Koenig L, Gu Q. Growth of ambulatory surgical centers, surgery volume, and savings to medicare. Am J Gastroenterol 2013; 108: 10-5.
10. Chin KR, Coombs AV, Seale JA. Feasibility and patient-reported outcomes after outpatient single-level instrumented posterior lumbar interbody fusion in a surgery center: preliminary results in 16 patients. Spine 2015; 40: E36-42.

11. Chin KR, Pencle FJ, Coombs AV, Packer CF, Hothem EA, Seale JA. Eligibility of outpatient spine surgery candidates in a single private practice. Clin Spine Surg 2017; 30: E1352-8.

12. Chin KR, Pencle FJ, Coombs AV, Brown MD, Conklin KJ, O'Neill AM, et al. Lateral lumbar interbody fusion in ambulatory surgery centers: patient selection and outcome measures compared with an inhospital cohort. Spine 2016; 41: 686-92.

13. American Society for Gastrointestinal E. Ambulatory Surgery Centers: A Positive Trend In Healthcare: Ambulatory Surgery Center Association; 2011. Available from: http:/www.asge.org/uploadedFiles/Members Only/Practice_Management/Ambulatory Surgery Centers-Trend in Health Care.SRC - GoogleScholar.

14. McKee J, Stambough MBA MD J. "Pearls" for avoiding spine surgery complications 2015. Available from: http:/www.aaos.org/news/aaosnow/mar11/clinical6.aspSRC - GoogleScholar.

15. Chin KR, Pencle FJR, Kubik J, Coombs AV, Seale JA, Hothem EAH et al. Avoidance of wrong level surgery in the lumbar spine: Report 2015; 4: 257.

16. Carneiro AV. Estimating sample size in clinical studies: basic methodological principles. Rev Port Cardiol 2003; 22: 1513-21.

17. Awad BI, Lubelski D, Shin JH, Carmody MA, Hoh DJ, Mroz TE et al. Bilateral pedicle screw fixation versus unilateral pedicle and contralateral facet screws for minimally invasive transforaminal lumbar interbody fusion: clinical outcomes and cost analysis. Global Spine J 2013; 3: 225-30.

18. Tsirikos AI, Subramanian AS. Posterior spinal arthrodesis for adolescent idiopathic scoliosis using pedicle screw instrumentation: does a bilateral or unilateral screw technique affect surgical outcome? J Bone Joint Surg Br 2012; 94: 1670-7.

19. Eliades P, Rahal JP, Herrick DB, Corliss BM, Riesenburger R, Hwang S et al. Unilateral pedicle screw fixation is associated with reduced cost and similar outcomes in selected patients undergoing minimally invasive transforaminal lumbar interbody fusion for 14-5 degenerative spondylolisthesis. Cureus 2015; 7: e249.

20. Wang L, Wang Y, Li Z, Yu B, Li Y. Unilateral versus bilateral pedicle screw fixation of minimally invasive transforaminal lumbar interbody fusion (MIS-TLIF): a meta-analysis of randomized controlled trials. BMC Surg 2014; 14: 87. 